\title{
Utilizando Agentes Pedagógicos Animados como uma abordagem não restritiva ao Gaming The System
}

\author{
Animated Pedagogical Agents as a non-restrictive approach to Gaming The System
}

\author{
Thiago Marquez Nunes \\ Patrícia A. Jaques \\ Av. Unisinos, 950 Bairro Cristo Rei - CEP 93.022-000 São Leopoldo, Brazil \\ Programa Interdisciplinar de Pós-Graduação em Computação Aplicada (PIPCA) \\ Universidade do Vale do Rio dos Sinos (UNISINOS) \\ nunes.thiago@live.com,pjaques@unisinos.br
}

\begin{abstract}
Resumo Sistemas Tutores Inteligentes apresentam grande potencial como ferramenta computacional de apoio a aprendizagem por permitir um acompanhamento individualizado do estudo do aprendiz. No entanto, a efetividade desses sistemas é muitas vezes reduzida por comportamentos do aluno, tais como o Gaming The System, quando ele tenta tirar vantagem das propriedades do tutor para avançar rapidamente na resolução dos problemas. Com o objetivo de minimizar o Gaming The System e, portanto, melhorar a experiência de aprendizagem do aluno, o presente artigo propõe o emprego de Agentes Pedagógicos Animados como abordagem não-restritiva ao comportamento. Foram desenvolvidos dois agentes com traços de personalidades diferentes. Eles respondem quando o aluno faz o Gaming The System por pedidos sucessivos de dicas, mostrando que estão cientes deste comportamento inadequado do aluno. As diferentes abordagens mostram que o tutor, através de suas ações, pode sim influenciar a maneira como o aluno encara a experiência e, dessa forma, desincentivar essa prática. Os resultados de um estudo conduzido com 41 alunos de uma escola privada, embora não tenham sido observados resultados estatísticos significativos, revelam que os agentes impactam diferentemente no comportamento do aluno segundo a sua personalidade.
\end{abstract}

Palavras-Chave: Inteligência Artificial, Sistemas Tutores Inteligentes, Agentes Pedagógicos Animados, Gaming The System

\begin{abstract}
Intelligent Tutoring Systems have a big potential supporting the learning process because they provide personalized assistance. However, many times the effectiveness of these systems is reduced because of some student's behaviors. One of these cases is the Gaming The System, when the student try to explore the tutor features in order to have a faster progress in the problem solving. In order to minimize Gaming The System and improve student's experience, this paper presents a non-restrictive approach to the behavior. We developed Animated Pedagogical Agents with different kinds of personality. The agents react when the learner "Game The System" by help seeking and show that they recognize the student's inappropriate behavior. The two different approaches show that the tutor can influence the way how the student face the experience through its actions and, in this way, discourage this practice. Even if the results of a research with 41 students from a private school are not statistically significant, they reveal that the agents with different personalities have a different impact in the learner's behavior.
\end{abstract}

Keywords: Artificial Intelligence, Intelligent Tutoring Systems, Animated Pedagogical Agents, Gaming The System 


\section{Introdução}

A popularização do computador passou a tornar cada vez mais evidente o potencial que ele tem como ferramenta de apoio na aprendizagem [4]. Isso, por sua vez, incentivou diversas pesquisas no desenvolvimento de Sistemas Tutores Inteligentes (STI) [41]. Tais pesquisas fizeram uso de técnicas de inteligência artificial para criar tutores efetivos, que conseguissem fornecer um ensino individualizado ao aluno. Corbett, Koedinger e Anderson [20] destacam uma série de contribuiçõos de pesquisas da área no que diz respeito à evolução de implementações, algoritmos e conceitos de inteligência artificial. Mais de 5\% das escolas dos Estados Unidos já fazem uso efetivo de Sistemas Tutores Inteligentes [8].

STIs atuam no sentido de proporcionar uma experiência mais próxima do ensino individualizado [24]. Um diferencial deste tipo de sistema é que o aluno pode aprender da sua maneira, sem necessitar acompanhar o ritmo dos colegas ou correr o risco de trabalhar com um conteúdo que ainda não domina, por exemplo [53].

O modo de construção de tais sistemas evoluiu de tal maneira que hoje existem tutores que visam interpretar a maneira humana de pensar, chamados tutores cognitivos $[33,44]$. Dentro dos tutores cognitivos, destaca-se o PAT2Math, projeto de pesquisa desenvolvido na UNISINOS, destinado à aprendizagem de equações algébricas de $1^{\circ}$ e $2^{\circ}$.

No que diz respeito à aplicação de STIs com alunos, o Gaming The System é um problema que influencia na experiência do aluno com o tutor e reflete no aprendizado final [10]. Baker et al [8] mensura que alunos que apresentam o comportamento aprendem apenas dois terços se comparados a outros que utilizam o tutor de maneira apropriada.

Tão importante quanto a identificação do problema como nocivo à experiência de aprendizado, é conceitua-lo de modo a entender o que configura Gaming The System. Em suma, Baker et al [8] define que o Gaming The System ocorre quando o aluno tenta "burlar" o meio de estudo proposto pelo tutor a fim de obter vantagem momentânea. Essa vantagem, segundo o autor, pode variar entre obter a resposta através de pedidos de dicas consecutivos ou tentar respostas aleatórias, no caso de tutores que trabalhem com problemas de resposta por múltipla escolha, para acertar a solução e passar para o próximo problema.

Diversas abordagens, apresentadas na seção de trabalhos relacionados, já atuaram no sentido de tratar a incidência do Gaming The System, porém apenas uma, retratada por Baker et al [9], o fez utilizando Agentes Pedagógicos Animados (APAs). Um Agente Pedagógico Animado, por sua vez, é um Agente Animado [30] com um papel educacional. Segundo Hayes-Roth e Doyle [28], agentes animados são agentes de software representados por um personagem animado. Lester et al [34] menciona que a presença de Agentes Pedagógicos Animados traz ganhos em motivação para o aluno, pois é simulada a presença do professor e as interações se dão de forma mais natural.

Dentro deste conceito, encaixa-se o estudo de Reeves e Nass [42] que apresenta experimentos que sustentam a ideia de que pessoas reagem a mídias da mesma maneira que reagem a outras pessoas. Segundo os autores, pessoas são educadas com computadores e esperam que a recíproca seja verdadeira, respeitando convenções sociais estabelecidas para as relações humanas.

O presente estudo propõe que agentes pedagógicos animados podem ser empregados como uma abordagem não restritiva ao Gaming The System. Acredita-se que o aluno se sentirá inibido a realizar Gaming The System se o agente mostrar ao aluno que está ciente que ele está apresentando este comportamento. $\mathrm{O}$ agente, integrado ao STI PAT2Math, atua fornecendo dicas relacionadas ao conteúdo para o aluno e faz intervenções quando percebe a ocorrência do Gaming The System. Vale ressaltar que essas intervenções foram implementadas apenas para quando o Gaming The System é percebido por pedidos sucessivos de dicas em função de o PAT2Math não possuir problemas com múltipla escolha e, portanto, motivar menos a ocorrência do comportamento através de tentativas deliberadas de solução.

$\mathrm{O}$ agente inserido no tutor pode ter dois comportamentos diferentes quando detectar o Gaming The System: adotar uma abordagem motivacional, demonstrando preocupação com o aprendizado do aluno; ou assumir que o aluno faz o Gaming The System para tentar avançar sem esforço nos desafios e adotar uma postura rígida e crítica em relação a isso. Essa abordagem se justifica no princípio relatado por Reeves e Nass [42], o que sugere que ambas as abordagens devem causar algum impacto na relação aluno-tutor e, portanto, ter influência na ocorrência ou não do comportamento.

Além disso, Lester et al [34], salienta que um agente animado influencia a experiência de aprendizagem e reflete nos resultados do aluno, por isso sua escolha para lidar com o Gaming The System. Dentre seus efeitos, está o aumento do canal de comunicação entre o aluno e o tutor e aumento da capacidade motivacional do tutor, bem como a empatia do aluno em relação a ele [31]. A abordagem de pesquisa é suportada, inclusive, pelos resultados dos estudos de Baker [7] que sugerem que a utilização de uma abordagem proativa em relação ao Gaming The System configura uma hipótese de pesquisa interessante de ser aprofundada.

Após a implementação dos agentes, o estudo foi avaliado com 41 alunos de uma escola privada de Porto Alegre que configuravam uma amostragem do público ao qual o tutor se destina. Após a coleta dos dados, os $\log s$ das interações dos alunos com o tutor foram analisados para verificar a ocorrência do comportamento durante essas interações. Com base na avaliação, foi possível 
estabelecer relações entre as atitudes dos agentes e a ocorrência do comportamento, além da influência no aprendizado do aluno.

O presente estudo está apresentado em mais oito seções além desta introdução. A Seção 2, referente a Sistemas Tutores Inteligentes, apresenta de modo breve os conceitos necessários dentro deste tema, bem com uma subseção sobre a arquitetura deste tipo de sistema e outra sobre Gaming The System. A Seção 3 traz os conceitos a cerca do PAT2Math e sua arquitetura, enquanto a Seção 4 aborda Agentes Pedagógicos Animados e os conceitos envolvidos nessa área que são relevantes para a presente pesquisa. A Seção 5 aborda o estudo de Reeves e Nass (2003) trazendo as regras e convenções sociais que se aplicam na relação através das diferentes abordagens sugeridas no estudo. A Seção 6, por sua vez, apresenta outros trabalhos desenvolvidos até o momento em torno do Gaming The System, as motivações para ocorrência do comportamento, abordagens de tratamento, entre outros. A Seção 7 apresenta a descrição detalhada do estudo no que diz respeito ao funcionamento e nas particularidades entre as duas abordagens utilizadas em relação ao $G a$ ming The System. A Seção 8 apresenta a avaliação do estudo implementado de modo a verificar se a presença do agente impacta no comportamento Gaming The System. Por fim, a Seção 9 apresenta as conclusões e considerações finais a cerca do estudo.

\section{Sistemas Tutores Inteligentes}

Com o objetivo de aproximar a experiência do aluno com o software do ensino individualizado, encontram-se os Sistemas Tutores Inteligentes (STI). A influência positiva no aprendizado acontece porque o sistema é projetado para desenvolver e saber os pontos em que o aluno possui mais dificuldades. Isso torna o aproveitamento da ferramenta e sua efetividade maiores, uma vez que o aluno tende a apresentar um desenvolvimento mais homogêneo e rápido [24].

Segundo Woolf [52], Sistemas Tutores Inteligentes contém modelos ricos e dinâmicos do conhecimento do aluno que descrevem as principais ideias que os alunos devem entender, assim como as suas concepções e falsas concepções. A autora ainda reforça que através da interação com STIs os alunos podem aprender em seu próprio ritmo, com seu próprio conhecimento e empenhar-se em fazê-lo com tutores direcionados para grupos ou para o auto aprendizado.

O primeiro Sistema Tutor Inteligente, SCHOLLAR [18] era um programa que propunha ao aluno um diálogo de iniciativa mista sobre a geografia da América do Sul. Basicamente, o tutor podia perguntar e responder questões em linguagem natural sobre este assunto e ainda manter o controle da estrutura de diálogo. A prova de sua importância é que seus modelos de conhecimento conceitual revolucionaram o entendimento tido até então a cerca de raciocínio inferencial e de perguntas e respostas. Além disso, o conhecimento gerado pelo seu desenvolvimento alimentou um programa de pesquisas e também inspirou sucessivos sistemas tutores posteriores [19, 46, 53].

A evolução das pesquisas no desenvolvimento de STIs motivou a construção dos chamados tutores cognitivos. Koedinger et al [33] conceituam um tutor cognitivo como aquele que possui um modelo psicológico do processo cognitivo envolvido na performance do aluno, independente de ele ter ou não ter sucesso em seus exercícios.

Segundo Koedinger e Corbett [32], eles são desenvolvidos com o intuito de reproduzir a lógica de raciocínio do aluno. Sobre a maneira como os tutores cognitivos se comportam, é sustentada a ideia de que eles favorecem o learning by doing. Esse método se caracteriza por colocar os alunos em situações que exijam a aplicação de conceitos e habilidades objetivas onde as instruções possam ser dadas diretamente nesse contexto ou em resposta às necessidades dele. Os autores destacam também a relevância desse processo no que diz respeito à maneira como seres humanos aprendem. Os tutores cognitivos têm duas tarefas principais: monitorar o desempenho do aluno, fornecendo instruções coerentes com o contexto; e monitorar o aprendizado do aluno, selecionando através disso os próximos desafios.

Vanlehn [48] apresenta o conceito de loops internos e externos, os quais são responsáveis por executar as ações mencionadas acima. O primeiro pode ser utilizado para fornecer feedbacks, dicas e atualizar o modelo do aluno, enquanto o segundo baseia-se no que ocorreu no loop interno para determinar a próxima tarefa do aluno. Em outras palavras, o loop interno é o que ocorre em cada interação com o tutor dentro de uma tarefa, o externo, por sua vez, inicia e finaliza junto de cada tarefa.

Vanlehn [48] salienta inclusive que essa formatação não é obrigatória, podendo o STI não possuir loop interno. Neste caso, o autor considera que o sistema perde em vários aspectos, como empatia e qualidade no feedback, por exemplo.

Do ponto de vista da arquitetura, um STI pode ser organizado nos seguintes módulos: base de domínio, modelo do aluno, tutor ou módulo pedagógico e a interface com o usuário [20, 41]. Segundo Psotka, Massey e Mutter [41], a base de domínio é responsável pelo conhecimento e expertise do tutor, o modelo do aluno guarda as informações a cerca dos conhecimentos do aluno e o módulo pedagógico aplica o conteúdo de acordo com o que o aluno sabe, garantindo que estes estejam alinhados com a estratégia de ensino. Por fim, tudo isso interage com o aluno através de uma interface que deve ter um perfil intuitivo e bastante amigável.

Para melhorar a experiência do aluno com o tutor investiu-se no desenvolvimento de técnicas de feedback sobre o problema proposto. No que diz respeito a esse subsídio que o tutor fornece ao aluno, Vanlehn [48] apre- 
senta as categorizações que este pode ter e também os momentos em que pode ocorrer (imediato, não imediato e sob demanda). Sobre a apresentação de dicas, existem alguns problemas e cuidados, os quais merecem atenção, como o momento em que ela é fornecida, qual próximo passo deve ser sugerido e como lidar com outros aspectos envolvidos na atividade, de modo a maximizar o aprendizado, controlando a frustração e permitindo que o aluno termine a resolução do problema.

No que tange às dicas, Aleven e Koedinger [2] trazem uma série de características interessantes que permitem entender o funcionamento desses sistemas. Para os autores, um ponto crucial é o fornecimento de dica inserida no contexto do problema que o aluno está resolvendo. Outro fator que exerce influência no aprendizado é o tutor prover dicas que façam o aluno raciocinar sobre o problema e não puramente fornecer respostas. Um exemplo disso são as dicas progressivas, que fazem com que o aluno vá lembrando os tópicos necessários para a resolução do problema e se tornam mais profundas a cada solicitação. Segundo os autores, a dica progressiva, por si só, não elimina a possibilidade de a resposta ser fornecida ao aluno. A resposta se torna o último estágio das dicas, mas a estrutura auxilia no sentido de que ela força que o aluno revisite todo o conteúdo exigido para tentar, por si só, entender como resolver o problema proposto.

\subsection{Gaming The System}

Apesar de visarem o aprendizado e serem pensados de maneira a incentivar o aluno a aproveitar a experiência com o tutor, nem sempre STIs são usados da maneira correta. Em alguns casos, o aluno tenta, inclusive, "burlar" o tutor a fim de obter vantagem momentânea, seja a resposta final do problema proposto ou avançar mais rapidamente nas atividades. Isso é considerado um mau uso e esse comportamento é chamado de Gaming The System [8]. O primeiro estudo a relata-lo foi feito por Tait, Hartley e Anderson [47], mas o nome do Gaming The System só foi definido por Figlio e Getzler [23].

O comportamento se manifesta das seguintes maneiras: (i) pedidos sistemáticos e sucessivos de ajuda, se valendo do sistema de ajuda progressivo dos tutores, onde em certo ponto o sistema fornecerá a resposta do problema ao aluno; (ii) ou tentativas sucessivas de responder ao problema com respostas aleatórias. No primeiro caso, o aluno sabe que ele ganhará a resposta após $\mathrm{X}$ solicitações de ajuda e, portanto, faz essa solicitação de maneira sistemática até que a resposta seja provida. Já o segundo acontece principalmente nos sistemas em que a resposta se dá através de alternativas; o aluno "chuta" as respostas, até que acerte a correta e possa, portanto, passar para o próximo desafio [8].

Baker et al [8] identifica duas razões para que esse comportamento aconteça. A primeira é o aluno ter uma orientação para o seu desempenho ao invés do aprendizado, assim ele entende que é importante avançar rápido na execução das atividades e simplesmente dar as respostas certas aos problemas propostos. Ou seja, ele entende que quanto mais desafios ele passar, melhor ele está indo na prática com o tutor. A outra é o aluno ter dificuldade com determinado conteúdo. Dessa forma, ele não se propõe a aprender o conteúdo que ele tem dificuldade, optando basicamente por adotar um comportamento sistemático que o faça evitar os problemas em que ele teria de dispender maior esforço para resolver.

Gaming The System não seria um problema se não tivesse influência negativa no aprendizado do aluno [10, 47]. Baker et al [8] ressalta em seu estudo que alunos que apresentaram o comportamento aprenderam em média dois terços do que foi aprendido por alunos que utilizaram o tutor de maneira adequada. Vale salientar que os alunos que participaram dos testes possuíam conhecimentos prévios e habilidades acadêmicas semelhantes.

Em função do efeito negativo do comportamento, Baker et al [8] aponta duas maneiras de atuar sobre sua ocorrência quando isso se dá através de pedidos consecutivos de ajuda. Como primeira abordagem, o autor menciona a existência de tutores que não fornecem a resposta final em suas dicas. A outra opção é restringir o uso das dicas através de travas de tempo. Além disso, nos casos em que o comportamento se manifesta por tentativas deliberadas de resolução, o autor sugere que o conhecimento exigido pelo problema seja "comprovado" através da resolução de um problema sem nenhum passo errado.

Em relação às tentativas de bloqueio ou tratamento desse comportamento [1, 14], elas não demostraram tanta efetividade, principalmente pelo fato de que os alunos buscam uma nova maneira de pratica-lo [9]. No caso de utilizar uma estratégia restritiva, é importante entender o que motiva o aluno a fazer o Gaming The System, pois por vezes ele pode não ser nocivo, o aluno pode estar tentando evitar passos e problemas que ele já esteja habituado e, portanto, sejam exaustivos [9]. Baker, Corbett e Koedinger [10] caracterizam o comportamento como diretamente ligado à motivação do aluno para a utilização do tutor, no sentido de ele estar orientado a puramente avançar ou em aprender. Os autores também salientam que alunos inseridos em um ambiente inteligente de aprendizagem são mais motivados que alunos que frequentam aulas tradicionais.

\section{PAT2Math}

Dentro do contexto tradicional de aula, a matemática sempre se mostrou um desafio para muitos alunos, principalmente quando, entre o $7^{\circ}$ e $8^{\circ}$ ano do Ensino Fundamental, passam a enfrentar a mudança do pensamento puramente aritmético para o pensamento algébrico. Isso motivou o desenvolvimento do PAT2Math, projeto de pesquisa da UNISINOS que tem o objetivo de tornar essa mudança menos traumática e auxiliar os alunos a desenvolver o pensamento algébrico através de um acompa- 
nhamento individualizado [44]. PAT2Math é um STI com foco na área de álgebra, mais especificamente no ensino de equações de $1^{\circ}$ e $2^{\circ}$ grau com apenas uma incógnita [45].

Sefrin, Rubi e Jaques [45] ressaltam a disponibilidade de se utilizar o sistema de forma modularizada como um diferencial do projeto. Cada módulo, como o PATEquation ou o PATSolver, possui suas próprias interfaces, inclusive. Além disso, é possível que o aluno resolva a equação proposta da maneira que preferir desde que respeite as regras algébricas.

Dentro deste conceito de módulos, o PAT2Math se apresenta como um ambiente web que possui as explicações e fornece o subsídio para que, no PATEquation, o aluno resolva os problemas propostos. O PATSolver, por sua vez, é o módulo resolvedor de equações, utilizado para validar os passos e soluções propostas pelo aluno [45].

A interface do PATEquation, representada na Figura
1 , se mostra intuitiva. $\mathrm{O}$ aluno resolverá as equações no espaço verde que representa um quadro negro; nos quadros "Operações" (quadros de botões à direita), constam todas as operações que podem ser utilizadas no processo de resolução de uma equação. Além dessas funcionalidades, há um quadro de mensagens (no canto inferior esquerdo), responsável por exibir orientações a cerca dos últimos eventos e dicas solicitadas pelo aluno, bem como o botão "Dica" (botão no quadro amarelo na parte inferior da Figura 1), que instrui quanto à próxima operação a ser realizada.

$\mathrm{Na}$ parte superior da interface, é possível verificar a pontuação do aluno, onde ele começa com 10 pontos e essa pontuação diminui com eventuais erros. Ao lado do painel de pontuação há um indicador percentual do desempenho do aluno. Como sugerido em Corbett, Koedinger e Anderson [20], o ambiente foi desenvolvido para que o aluno sinta-se confortável no processo de aprendizagem e, portanto, tenha um melhor aproveitamento.

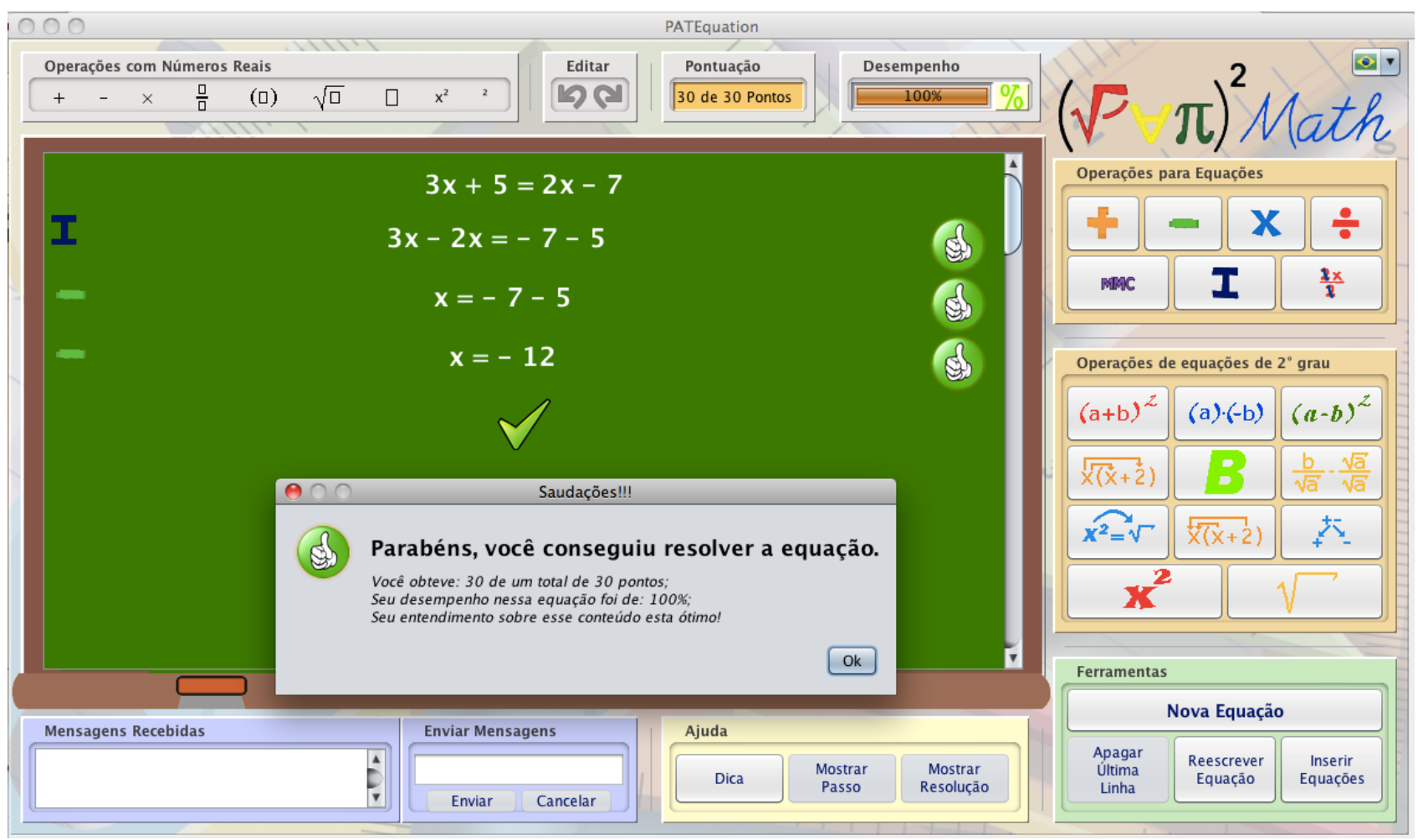

Figura 1: Interface do PAT2Math

No caso do PAT2Math, um ponto importante a ser observado é a capacidade do sistema de prover feedback em tempo real. Com isso, o aluno tem real noção do seu desempenho e também consegue entender seus erros e o motivo pelo qual eles aconteceram. Este retorno, proporcionado pelo STI, fez necessária a implementação de um módulo com as falsas concepções que o aluno pode ter, pois é importante que o aluno tenha conhecimento do motivo do seu erro e consiga, portanto, evoluir a partir disso [45].

Essa preocupação com as falsas concepções é outro ponto a destacar na implementação do tutor. No caso de o aluno errar um passo durante a resolução de uma equação, o sistema tentará repetir o erro do aluno, através de 
regras de resolução cadastradas previamente, para entender o motivo da falha e poder orientá-lo quanto ao caminho correto. Tais funcionalidades auxiliam no desenvolvendo do pensamento algébrico e permitem trabalhar diretamente nas dificuldades apresentadas pelo aluno [45].

Levando em consideração a sua arquitetura, o sistema possui basicamente os elementos citados por Psotka, Massey e Mutter [41]: Base de domínio, modelo do aluno, tutor e interface com o usuário. A base de domínio caracteriza-se por um sistema especialista que contém as regras que podem ser aplicadas na resolução de equações e também as falsas concepções que o aluno pode ter na sua aplicação; em estudo foram levantados os 56 erros mais frequentes no que diz respeito à resolução de equações de $1^{\circ}$ e $2^{\circ}$ grau com uma incógnita. O modelo do aluno é responsável por armazenar as informações a cerca do seu desenvolvimento e conhecimentos que ele possui, bem como seus pontos fortes e fracos, e, consequentemente, auxiliar na escolha dos exercícios propostos. O tutor é responsável por aplicar o conteúdo, requisitando e compilando as informações dispostas tanto na base de domínio quanto no modelo do aluno [45].

\section{Agentes Pedagógicos Animados}

Com o intuito de tornar a interação com Sistemas Tutores Inteligentes mais intuitivas, suas implementações passaram a contar com recursos multimídias [30]. Dentro destes recursos, encontram-se os Agentes Animados (AA). Eles são agentes de software representados por um personagem animado, sendo capaz de interagir com o usuário [28]. Sendo geralmente representações humanas virtuais, AAs se comunicam de maneira multimodal com o usuário através de voz, expressões faciais, olhar, gestos e movimentação corporal. A efetividade de um agente depende da sua credibilidade (believability): habilidade de desfazer a descrença do usuário em relação ao agente durante a interação. Acrescentam no que diz respeito à credibilidade e vivacidade do agente a expressão de emoções e a exibição de uma personalidade consistente [35].

Visando tornar-se credível, um agente deve ter a capacidade de manter-se sempre ativo, entretanto não deve tirar o foco do aluno. Ele deve poder realizar diversas interações, para as diferentes situações que possam ser necessárias, realizando cada uma delas de maneira singular, assim seu comportamento se torna mais próximo do comportamento humano, ou seja, deixa de parecer uma ação mecânica [28]. Alguns estudos anteriores [17, 26] permitem uma visão melhor a cerca das estratégias de movimentação e abordagem que são válidas para serem implementadas em um agente desse tipo.

Com relação à arquitetura, os agentes animados normalmente são divididos em duas partes, corpo e mente. Como os próprios nomes sugerem, a primeira refere-se à parte visual do agente, contemplando inclusive as ações e animações dele, e a segunda à inteligência do agente, controlando essas ações e interações com o usuário do sistema. O corpo deve ser capaz de representar e passar as ações solicitadas pela mente [37]. É importante que o projeto de arquitetura do agente contemple a necessidade de que ele seja conversacional, empático, social, inteligente e coerente, de modo a se tornar bastante semelhante a um indivíduo [27].

Quando um Agente Animado é implementado em um Sistema Tutor Inteligente, este passa a ser chamado de Agente Pedagógico Animado (APA) [30]. Este, por sua vez, tem o intuito de promover o processo de construção do conhecimento, tornando o aprendizado mais eficaz e envolvente [31]. A implementação de um APA geralmente ocasiona um aumento significativo no que diz respeito à aproximação do aluno com o software, trazendo ganhos sob diversos aspectos pedagógicos. Além disso, a relação com o agente traz ganhos em motivação para o aluno, pois é simulada a presença do professor e as interações se dão de forma mais natural [34].

Segundo Lester et al [34], o uso de um agente animado influencia a experiência de aprendizagem e reflete nos resultados do aluno. Além disso, o estudo mostra também que a identificação do agente com o aluno existe mesmo na utilização do agente sem nenhuma interação com o usuário. Neste caso, foram realizados testes em que o agente estava presente, mas não praticou nenhuma ação.

Com relação às funções que podem ser executadas pelo agente pedagógico animado, ele pode utilizar gestos para contribuir nas explicações ou mesmo incentivar o aluno com palavras e animações motivacionais. $\mathrm{O}$ agente pode também passar as informações do conteúdo ao qual o sistema se dedica de uma maneira mais amigável e antropomórfica, assumindo, de fato, o papel de tutor [30].

Além dos pontos já apresentados, o agente pode ser o responsável por fornecer o retorno em relação aos resultados obtidos pelo aluno, pode fazer uso de comportamento não verbal para se aproximar do aluno, tal qual ocorre na interação entre pessoas no mundo real [31]. Buisine e Martin [17] inclusive comprovam a relevância da comunicação não verbal neste tipo de implementação.

A partir do momento em que se passa a estudar o uso de uma figura que visa representar um tutor humano dentro do sistema, torna-se inevitável considerar uma série de estudos em relação a como este personagem deve se comportar para parecer mais humano e, portanto, atingir seu principal objetivo. Com relação à sintetização de gestos, foram pesquisadas diversas maneiras de fazê-la para torna-la mais próxima da forma humana de se comportar [26].

Com base neste estudo, foi possível estabelecer um modelo de avaliação qualitativa dos gestos do agente. Este modelo proposto baseia-se em seis atributos que, combinados, fornecem subsídio para a avalição da expressividade dos gestos. São eles [26]: (i) Ativação global: tempo em que há movimentação durante um "turno" 
de conversação; (ii) Extensão espacial: amplitude de movimentos; (iii) Extensão temporal: duração dos movimentos; (iv) Fluidez: suavidade e continuidade dos movimentos; (v) Força: propriedades dinâmicas do movimento; (vi) Repetição: tendência de repetição rítmica de movimentos específicos.

Além disso, foi percebida a importância do aspecto complementar das linguagens verbal e não verbal no comportamento do agente animado faz o papel de tutor. No que diz respeito a gestos e falas, existem três estratégias diferentes de distribuição, segundo Buisine e Martin [17]: redundante, complementar e controlada. Na primeira os gestos produzem informações duplicadas em relação à fala, na segunda a informação é distribuída entre gestos e fala e na terceira os gestos não possuem informação semântica e apenas a fala que passa as informações. Quando avaliada apenas a questão de fixação e entendimento das informações, a estratégia de redundância se mostrou mais apropriada [17].

No que tange aos gestos do agente, Loyall e Bates [35] reforçam o quanto a expressão de emoções pode influenciar na sua credibilidade. Jaques [29] apresenta em seu estudo dados a cerca do potencial dos Agentes Pedagógicos Animados para retratar emoções e, inclusive, lidar com as emoções do aluno enquanto este interage com o tutor. Essa abordagem é subsidiada, inclusive, por estudos da área de psicologia e pedagogia [3, 22, 16], que reforçam a ideia de que as emoções exercem influência direta na qualidade do aprendizado do aluno. Marchand [36], Vygotsky [49] e Piaget [40] corroboram esta visão principalmente no que diz respeito à relação aluno professor, uma vez que esta também é marcada pela necessidade de um vínculo afetivo para que o aluno sinta-se à vontade e motivado para aprender. Wallon [50] vai além e menciona a afetividade como o meio pelo qual as pessoas aprendem a se comunicar, sendo, portanto, peça fundamental da construção cognitiva do ser humano. Dentro dessa linha de pensamento, questões afetivas influenciam, inclusive nas escolhas das atividades que o aluno irá ou não realizar, bem como sua orientação frente a esses desafios.

Todas essas possibilidades de aplicação apresentadas, fazem com que os Agentes Pedagógicos Animados tenham, sobretudo, duas vantagens sobre as implementações anteriores: aumentam o canal de comunicação entre o aluno e o computador e aumentam a capacidade motivacional do computador e, em consequência, a empatia do aluno em relação a ele [31].

\section{The Media Equation}

É possível estabelecer um paralelo dos conceitos empregados na criação de Sistemas Tutores Inteligentes com os estudos de Reeves e Nass [42], onde são apresentados 35 experimentos que sustentam a ideia de que pessoas reagem a mídias da mesma maneira que reagem a outras pessoas. A ideia principal do estudo é que pessoas são educadas com computadores e esperam que a recíproca seja verdadeira; ou seja, dada uma convenção social como "quando alguém pergunta sobre si mesmo, as pessoas tendem a responder de maneira mais positiva", isso se aplica a computadores. No caso apresentado, quando um software pergunta sobre si mesmo, as pessoas tendem a dar respostas mais positivas se comparado à quando um software avalia outro.

Fazendo uso de um nível de abstração maior e de um exemplo mais próximo da realidade diária das pessoas e que foi provido pelo próprio estudo de Reeves e Nass [42]: é natural as pessoas gritarem com um aparelho eletrônico que não funciona, como a televisão, ou ainda reagirem de forma mais positiva quando um personagem ou entrevistado se dirige diretamente ao público ou se aproxima da câmera, também na televisão.

Reeves e Nass [42] ainda provam que isso fica evidente em diferentes esferas da relação das pessoas com mídias. Sejam ações, personalidade, emoções, regras sociais ou aparência, qualquer um desses fatores pode aproximar ou afastar pessoas de uma determinada mídia. Neste caso, lembrando os pontos levantados em relação à implementação de um APA, é possível entender o favorecimento de convenções sociais simples das relações humanas, pode, de fato, facilitar a relação tutor-aluno, tornando-a mais próxima à relação professor-aluno.

Para a presente pesquisa, uma categoria de regras apresentadas por Reeves e Nass [42] que precisa ser abordada é a que considera os julgamentos. Nesse sentido, as regras validadas pelo estudo que se enquadram aqui são: $O$ desempenho elogiado por um computador será percebido como superior frente a um desempenho criticado por um computador; um computador que elogia outro será percebido como mais amigável; e um computador que critica outro será considerado menos amigável.

Há ainda uma categorização de regras que se baseia no tipo de personalidade tanto da mídia quanto da pessoa. Nessa esfera, pessoas e mídias são divididas em dominantes e submissos. Uma tendência importante nesse ponto é que as pessoas gostam das mídias com as quais elas se parecem, ou seja, pessoas dominantes preferirão mídias dominantes, enquanto pessoas submissas se sentirão mais à vontade com mídias submissas [42].

Por fim, outra área de relacionamento entre pessoas e mídias que é abordada por Reeves e Nass [42] e tem relação direta com o presente estudo é no que tange à emoção. Acerca disso, a primeira regra é que a primeira avaliação de uma experiência sempre se resumirá a um julgamento de bom ou ruim. Junto disso, são apresentadas algumas convenções a respeito de positividade e negatividade: (i) As pessoas não vão gostar de mídias negativas; (ii) As pessoas prestarão mais atenção nas mídias negativas do que nas mídias positivas; (iii) As pessoas lembrarão mais das mídias negativas do que das positivas; (iv) As pessoas terão uma retenção melhor das 
informações recebidas depois de uma mídia negativa do que da informação recebida depois de uma mídia positiva; (v) As pessoas terão uma retenção melhor das informações recebidas antes de uma mídia positiva do que da informação recebida antes de uma mídia negativa.

Como já mencionado, os conceitos apresentados são convenções sociais humanas que tiveram sua equivalência testada e comprovada no que diz respeito a relações com mídias. Dentro deste cenário, esses pontos passam a merecer consideração e, inclusive, servirem de parâmetro para a definição de estratégias de implementação de mídias que dependam da qualidade de interação para um melhor resultado. Somam-se a essas justificativas alguns fatores abordados por Reeves e Nass [42] nas conclusões de seus estudos como o fato de o Media Equation ocorrer automaticamente e da necessidade de manter qualquer mídia o mais orgânica às dinâmicas já conhecidas pelos seres humanos.

\section{Trabalhos Relacionados}

Partindo da abordagem com o uso de alguma espécie de trava quando identificado o Gaming The System, Beck [14] apresenta um modelo que calcula o tempo que o aluno deve dispender para a resolução de cada problema e o compara com o tempo que o aluno realmente levou. Enquanto esses tempos não estivessem alinhados, o agente trocava as mensagens de dicas por mensagens como "Tente novamente" ou "Avalie sua resolução". Tais ações eram baseadas no conceito de que, no caso de o aluno estar engajado no seu aprendizado, ele demoraria um determinado tempo para solucionar cada problema, e esse tempo, por sua vez, era estabelecido pela complexidade do desafio proposto. Um ponto a ressaltar é que o modelo conseguia se adaptar à evolução do aluno, adotando o tempo que o aluno tem demonstrado necessário na resolução de problemas semelhantes.

Em relação aos resultados que dizem respeito ao $G a$ ming The System, Beck [14] ressalta que uso de uma estratégia restritiva teve impacto negativo no que tange ao engajamento do aluno. Com base nisso, o autor destacou como um desafio futuro a implementação de um tutor que conseguisse lidar com o engajamento do aluno e mantê-lo feliz sem ferir conceitos pedagógicos que estejam envolvidos nessa relação.

Baker et al [9] apresenta a primeira tentativa de tratamento do Gaming The System através do uso de um APA (Agente Pedagógico Animado). Neste estudo, foi inserido um agente, chamado Scooter, que consistia na figura de um cachorro, que demonstrava sua insatisfação toda vez que ele considerava que o aluno estava fazendo Gaming The System. O escopo da pesquisa se restringia a quando o comportamento é praticado através de erros sucessivos. Neste caso, ao identificar o comportamento, o agente considerava que aquele tópico deveria ser revisto pelo aluno e, posteriormente, propunha novos problemas envolvendo a mesma área de conhecimento.

Através da avaliação da pesquisa de Baker et al [9], percebeu-se uma melhora no desempenho dos alunos, porém ela não pode ser atribuída às ações de Scooter, mas sim à estrutura montada para tratar o comportamento, fazendo uso de exercícios de reforço, o que melhorou a experiência de aprendizado dos alunos. Tendo isso em vista, a contribuição desta pesquisa foi mostrar que através de uma abordagem correta em relação ao Gaming The System, o aluno pode sim ter uma melhor experiência de aprendizado com o tutor. Ficou aberta, porém, a discussão a respeito de qual seria a abordagem mais apropriada.

Beal, Qu e Lee [15] promovem uma discussão que associa a motivação do aluno à maneira como ele interage com o tutor. Dentro das avaliações realizadas, alunos que se consideram desmotivados para o estudo da matemática mostraram tendência de utilizar incorretamente os recursos providos pelo STI se comparados a alunos que se declararam altamente motivados. Como ações não desejadas, o estudo considerou o abuso de dicas e a tentativa de resolução independente do problema. O modelo proposto pelos autores baseia-se em feedback do próprio aluno para montar estratégias de reengajamento, motivando-o para estar orientado ao aprendizado. O estudo é importante por abrir espaço para o estudo do tratamento do Gaming The System através de estratégias motivacionais.

Levando em conta essas questões motivacionais, Walonoski e Heffernan [51] entenderam que o Gaming The System pode ser abordado por duas maneiras: intervenções ativas e passivas. No primeiro caso, há uma interferência direta na experiência do aluno com o tutor, sugerindo que ele peça ajuda ao professor ou direcionando mensagens de encorajamento, por exemplo. No segundo, por sua vez, ficam visíveis para o aluno informações a cerca do seu desempenho geral, ou seja, o aluno pode ver registradas no tutor cada uma de suas interações, mas não há interferência na maneira como ele interage com o STI. Walonoski e Heffernan [51] fizeram experimentos utilizando intervenções passivas e ativas quando os alunos apresentavam o comportamento. Enquanto as intervenções passivas, que consistiam em prover feedback contínuo das ações e desempenho do aluno, foram melhores aceitas pelos professores, o estudo provou que uma combinação das duas abordagens seria a estratégia mais efetiva para diminuir a ocorrência do comportamento.

Ainda levando em conta a experiência do aluno com o tutor, o estudo descrito por Arroyo et al [5] mostra o impacto de uma série de intervenções não invasivas para quando o aluno não se mostra comprometido com o uso do tutor. Essas intervenções consistiam em dicas a respeito de comportamentos que eram ou não interessantes do ponto de vista pedagógico para o aprendizado do aluno, 
ou seja, o tutor agia no sentido de guiar o aluno sobre quais ações eram ou não favoráveis ao aprendizado dele. Essa abordagem tornou possível identificar uma série de melhorias na experiência do aluno com o tutor, como a atribuição de mais características humanas a ele, um sentimento de que o aluno aprendeu mais e também de que o tutor o auxiliou melhor na construção deste aprendizado. Arroyo et al [5] atribuíram esses resultados às práticas não invasivas, pois sempre que houvesse um desvio de comportamento por parte do aluno, o tutor tomava uma ação que permitisse que ele voltasse a se comprometer seriamente com o aprendizado. Além disso, as ações tomadas pelo aluno eram registradas de maneira visível a ele, o que aumentou o tempo de resolução dos problemas. Esse efeito foi atribuído a um pudor maior dos estudantes na hora de tomar as ações por receio em receber um feedback negativo.

Baker [6] propõe um modelo baseado em Critérios de Informação Bayesianos, que permite identificar, entre as diferentes razões para que um aluno pratique o Gaming The System, qual mais o motiva. Esse estudo serviu de base para a construção do modelo apresentado em Baker et al [12], que visa prever quando o aluno está realizando o mau comportamento e também estabeleceu um paralelo importante entre o Gaming The System e as emoções sentidas pelo aluno no momento do uso do tutor.

Para ilustrar essa relação, Baker et al [12] sugerem que, no tratamento do Gaming The System, se considere, por exemplo, que quando um aluno concentrado pede ajuda, ele não costuma errar a tentativa posterior ao pedido de ajuda. No caso de um aluno confuso, ele normalmente tem ações mais lentas que o normal e também tem um histórico com mais respostas incorretas e um número maior de pedidos de ajuda. Estudantes frustrados tendem a cometer mais erros e a evitar a ajuda, apesar de, mesmo assim, possuírem um histórico grande de erros e pedidos de ajuda em comparação aos outros perfis. Este estudo também abriu a discussão para se o Gaming The System não seria a manifestação da própria frustração do aluno.

Baker et al [13] apresenta um estudo que busca as razões pelas quais os alunos praticam o Gaming The System. Dentro deste estudo, foram utilizados dois ambientes de aprendizagem diferentes que permitiram que se estabelecesse a relação entre o comportamento e as diferentes motivações, emoções e comportamentos dos alunos. Como conclusão, ficou bastante evidente que os objetivos do aluno ao utilizar o tutor são uma das principais causas da ocorrência do comportamento.

Essa descoberta motivou uma nova pesquisa, apresentada em Baker et al [11], que apresenta mudanças na arquitetura dos tutores a fim de verificar seu impacto frente ao comportamento do aluno. Como contribuição, o estudo foi capaz de identificar características do software que representam $56 \%$ da variação do comportamento. Dentre estas características que influenciam a incidência do comportamento, está o uso de questões ambíguas, muito abstratas ou não explicadas de maneira clara. $\mathrm{O}$ estudo ainda associa o Gaming The System à quantidade de texto não relacionado à tarefa no enunciado do problema.

Por fim, Baker et al [11] traz uma série de boas práticas no que diz respeito à STIs que visam melhorar a experiência de aprendizado no que tange ao Gaming The System. São elas: barra de ferramentas pouco confusa e autoexplicativa, reestruturação das dicas que parecem não contribuir para a melhora no desempenho do aluno, utilizar exemplos interativos ou diagramas quando for realizada a apresentação de conteúdo que precisa de um maior nível de abstração e utilizar textos que aumentam o interesse do aluno ao problema, quando o problema precise ser descrito através de texto.

Avançando nos estudos das causas do comportamento, Gong et al [25] apresenta a integração de um modelo de rastreio de conhecimento a um detector de Gaming The System em um tutor. Neste caso, o objetivo foi identificar se, quando o aluno realiza o comportamento, ele tem ou não o conhecimento necessário para resolver o problema proposto. $\mathrm{Na}$ avaliação do experimento, identificou-se que a quantidade de vezes que o aluno faz o $G a$ ming The System está associada a um menor aprendizado, inclusive nos exercícios nos quais ele não fez uso do comportamento. Além disso, verificou-se uma tendência de o comportamento ocorrer nos problemas que o aluno tem um baixo nível de conhecimento nos assuntos requeridos. Por fim, uma associação importante trazida pelo estudo é de que o comportamento é previsto de maneira mais assertiva quando relacionado ao perfil de uso que o aluno faz do tutor que com os conteúdos sabidos por ele ou não.

Muldner et al [38], por sua vez, discorre sobre quais as causas e respectivos impactos para o aluno quando este pratica o Gaming The System. Dentro disso, a pesquisa se propunha a responder qual era o melhor meio de prever a ocorrência do comportamento, o problema proposto ou o próprio aluno. Como resultado final, identificou-se o aluno como o melhor meio de prever quando o Gaming The System ocorrerá, o que vem a corroborar com a visão mostrada em Gong et al [25]. Após esse resultado, o STI utilizado para os testes foi ainda avaliado com base nas características apresentadas em Baker et al [11], comparando e citando melhorias que poderiam ser aplicadas, principalmente no sistema de dicas do tutor para que esse se tornasse mais claro e motivasse um uso mais correto por parte do aluno. Além disso, notou-se a necessidade de aplicar melhorias no modelo de previsão do comportamento, que utilizava técnicas de aprendizado de máquina e redes Bayesianas para identificá-lo.

O estudo promovido por Roll et al [43] se restringe ao Gaming The System praticado por pedidos sucessivos de ajuda. Neste caso, os autores se propuseram a identificar se dicas da parte do tutor em relação à utilização correta da ferramenta de ajuda do tutor teriam efeito sobre o 
comportamento indesejado. Para tal foi feita a implementação de um tutor do uso de dicas em um STI cognitivo já consolidado para o ensino de geometria. Esse tutor de dicas podia identificar os pedidos consecutivos e o abuso das dicas e agia em cima disso aconselhando o aluno às melhores práticas do uso das dicas do tutor de geometria. Com relação aos resultados, notou-se uma diminuição na incidência do comportamento inclusive depois que o tutor de dicas fora desativado, bem como um melhor aproveitamento das dicas e do conteúdo em si no estudo de novos assuntos.

Com base nos trabalhos apresentados, é possível perceber os avanços nas questões que motivam os alunos a praticar o Gaming The System, mas ainda não há uma diretriz clara de qual a estratégia mais efetiva para diminuição do comportamento. Dentro deste cenário, a presente pesquisa visa trazer um olhar sob uma perspectiva diferente, não avaliada até então que é considerar aspectos das relações humanas em uma implementação de um Agente Pedagógico Animado com o intuito de diminuir a ocorrência do Gaming The System por pedidos sucessivos de ajuda.

\section{Descrição do Trabalho}

A presente seção apresenta o trabalho proposto cujo objetivo é diminuir o Gaming The System através das mensagens de APAs que mostram ao aluno que estão cientes do comportamento. Para abordar o problema, foi inserido um agente animado no sistema tutor inteligente PAT2Math. Esse agente pode ter dois comportamentos diferentes em relação ao Gaming The System: adotar uma abordagem motivacional, demonstrando preocupação com o aprendizado do aluno, ou adotar uma postura rígida e crítica em relação ao comportamento, como se o aluno estivesse tentando enganar o tutor.

A abordagem visa permitir avaliar o impacto frente à hipótese de que o aluno faz o Gaming The System porque imagina que o agente não é inteligente ao ponto de entender suas ações ou mesmo de ter consciência a respeito do que está acontecendo durante as interações. Os autores consideram que, no momento em que o agente demonstra que entende que o aluno está praticando o Gaming The System, ele se torna mais credível e, por consequência, o aluno vai ser mais cuidadoso na sua postura, assim como ele seria com um professor humano.

No que diz respeito à justificativa para a escolha de tal abordagem, ela se justifica no que afirmam Johnson, Rickel e Lester [31], que sustentam a ideia de que o uso de agentes animados aumenta o canal de comunicação entre o aluno e tutor e aumento da capacidade motivacional do tutor, bem como a empatia do aluno em relação a ele. Isso pode ser fundamentado, inclusive, no princípio relatado por Reeves e Nass [42], que prova a equivalência das convenções sociais humanas em relação às mídias. Por fim, Baker [7] afirma em seu estudo que vê as abor- dagens proativas e não restritivas como o futuro no que diz respeito à pesquisa sobre Gaming The System.

\subsection{Funcionamento e Arquitetura}

Para a implementação do detector de Gaming The System no PAT2Math, algumas definições foram necessárias. Dentro deste contexto, optou-se por restringir a ação do tutor a quando o comportamento ocorre por pedidos sucessivos de dicas, excluindo da pesquisa quando isso ocorre pela tentativa de resolução através da escolha de respostas aleatórias. A opção por essa restrição foi porque o PAT2Math não possui problemas com múltipla escolha e, portanto, motiva menos a ocorrência do comportamento através de tentativas deliberadas de solução.

Após a definição do escopo da pesquisa, um passo importante foi definir em conjunto com uma professora de matemática o que o tutor deveria considerar Gaming The System no caso da interação com o PAT2Math. Após uma análise do histórico de avaliações do projeto, tomouse por definição que o comportamento está evidenciado quando o aluno pede duas dicas em sequência ou mais sem realizar nenhuma interação com o tutor.

Em relação à implementação aqui apresentada, vale salientar que, levando em consideração a arquitetura descrita por Psotka, Massey e Mutter [41], ela foi realizada no módulo que controla a interface do tutor. Para implementação do agente animado, foi utilizado o framework DivaLite, desenvolvido por Corrêa [21], o qual o PAT2Math já estava preparado para ser integrado. Além disso, o agente utilizado tem a mesma fisionomia do agente implementado por Jaques [29] e apresentado na Figura 2. No que tange a funcionalidades desenvolvidas, a primeira delas foi a detecção do Gaming The System por pedidos excessivos de dicas. Para tal, o agente passou a monitorar as dicas pedidas pelo aluno e verificar se havia ou não interação com o tutor entre as dicas solicitadas em um mesmo problema. No caso de não ter havido nenhuma interação entre um pedido de dica e outro, o tutor considera que o aluno praticou Gaming The System.

Com o comportamento identificado uma primeira vez, o agente passa a agir com base nos traços de personalidade definidos. Para garantir o isolamento e reuso dessas regras, foi criada uma classe responsável por fazer apenas o controle da incidência do comportamento e da liberação ou não de intervenções do agente. Essa classe baseia-se em um valor percentual que determina a probabilidade de o aluno receber uma intervenção. Quando o aluno inicia a interação com o tutor, esse percentual de probabilidade de ação está zerado, o que garante a não ocorrência de intervenções caso o aluno não pratique o Gaming The System nenhuma vez.

Cada vez que o tutor verifica a ocorrência do Gaming The System, o fator que determina a probabilidade de uma intervenção ocorrer é acrescido de $15 \%$. Em outras palavras, cada vez que o aluno pratica o mau comportamento, aumentam as chances de o tutor interceder da forma co- 
mo está programado para fazê-lo, seja com uma abordagem amigável ou crítica. Essa probabilidade de ação relacionada ao Gaming The System é limitada a no máximo $90 \%$, o que quer dizer que 6 vezes que o comportamento for percebido são suficientes para garantir a ação máxima do agente sobre ele.

Para que o tutor não se restrinja a apenas exibir mensagens sobre a conduta do aluno, deixando de lado as dicas sobre como resolver o problema, as intervenções implementadas foram programadas de maneira a não ocorrer em sequência. Ou seja, é obrigatória a exibição de ao menos uma dica relacionada ao problema entre cada intervenção do tutor a respeito do mau comportamento.

A fim de proporcionar uma maior dinamicidade a estas intervenções, elas intercalam entre frases longas e curtas. Para cada traço de personalidade diferente foram determinadas dez frases longas e cinco frases curtas, o que possibilita quinze diferentes frases que são combinadas a três diferentes comportamentos gestuais no tutor amigável e quatro no tutor de postura crítica.

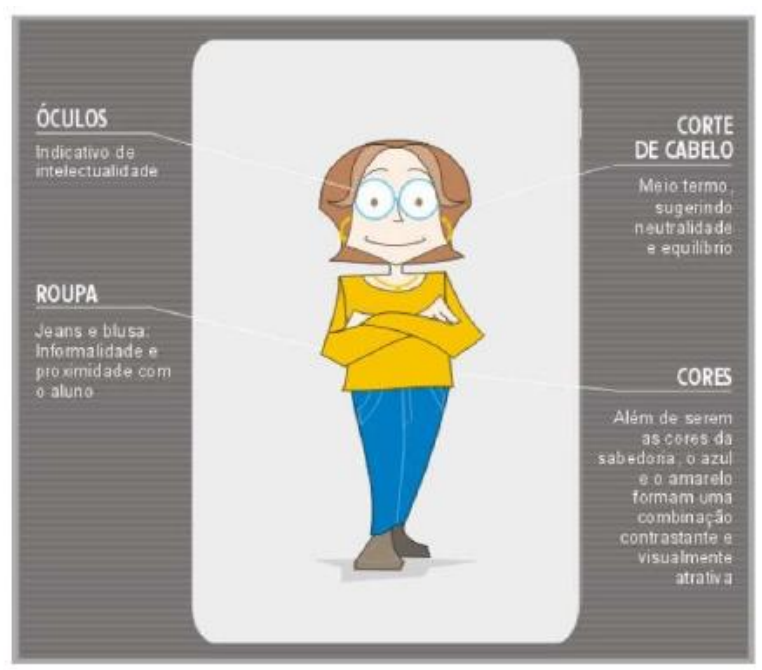

Figura 2: Corpo do Agente PAT

Tabela 1: Frases longas das intervenções do agente com os diferentes trações de personalidade

\begin{tabular}{|c|c|}
\hline Frases Amigáveis & Frases Críticas \\
\hline $\begin{array}{l}\text { Você aprenderá muito mais encontrando a res- } \\
\text { posta certa pelo seu próprio esforço do que me } \\
\text { pedindo dicas! }\end{array}$ & Não é feio pedir ajuda, mas abusar dela é! \\
\hline $\begin{array}{l}\text { O que você acha de tentar resolver a equação } \\
\text { mais um pouco antes de pedir uma dica? }\end{array}$ & $\begin{array}{l}\text { Você não sabe mesmo a resposta ou está tentando } \\
\text { me enganar? }\end{array}$ \\
\hline $\begin{array}{l}\text { Eu confio em você, sei que é capaz de resolver } \\
\text { o problema com seu conhecimento! }\end{array}$ & $\begin{array}{l}\text { Me sinto feliz de ajudar, mas você não está pe- } \\
\text { dindo ajudas demais? }\end{array}$ \\
\hline $\begin{array}{l}\text { Sei que o problema é difícil, mas você deve } \\
\text { persistir e tentar resolver a equação! }\end{array}$ & $\begin{array}{l}\text { Está tentando obter a resposta sem resolver o } \\
\text { problema? Isso não é bom para ti! }\end{array}$ \\
\hline $\begin{array}{l}\text { Posso até te dar dicas, mas será que você vai } \\
\text { aprender mais com isso? }\end{array}$ & $\begin{array}{l}\text { Me peça dicas apenas quando realmente precise, } \\
\text { caso contrário eu saberei! }\end{array}$ \\
\hline $\begin{array}{l}\text { Estou aqui para te ajudar, para isso é impor- } \\
\text { tante que você conheça seus limites! }\end{array}$ & $\begin{array}{l}\text { Você deve procurar minha ajuda apenas quando não } \\
\text { souber mais como prosseguir! }\end{array}$ \\
\hline $\begin{array}{l}\text { Pedir dicas na hora certa também vai fazer com } \\
\text { que você aprenda melhor. }\end{array}$ & $\begin{array}{l}\text { Tentar me enganar para conseguir a resposta só } \\
\text { vai prejudicar seu aprendizado! }\end{array}$ \\
\hline $\begin{array}{l}\text { Persistência é uma virtude necessária para o } \\
\text { sucesso nos estudos. }\end{array}$ & $\begin{array}{l}\text { Se eu sempre te der a resposta, você nunca apren- } \\
\text { derá! }\end{array}$ \\
\hline $\begin{array}{l}\text { Conto com você para resolver este problema! } \\
\text { Tente mais um pouco sozinho! }\end{array}$ & $\begin{array}{l}\text { Te ajudar é importante para mim, mas não gosto de } \\
\text { ser passado para trás! }\end{array}$ \\
\hline $\begin{array}{l}\text { Não desista agora! Que tal se esforçar um } \\
\text { pouco mais? Estou contigo! }\end{array}$ & $\begin{array}{l}\text { Você precisa de ajuda ou está buscando a resposta } \\
\text { pelo jeito mais fácil? }\end{array}$ \\
\hline
\end{tabular}




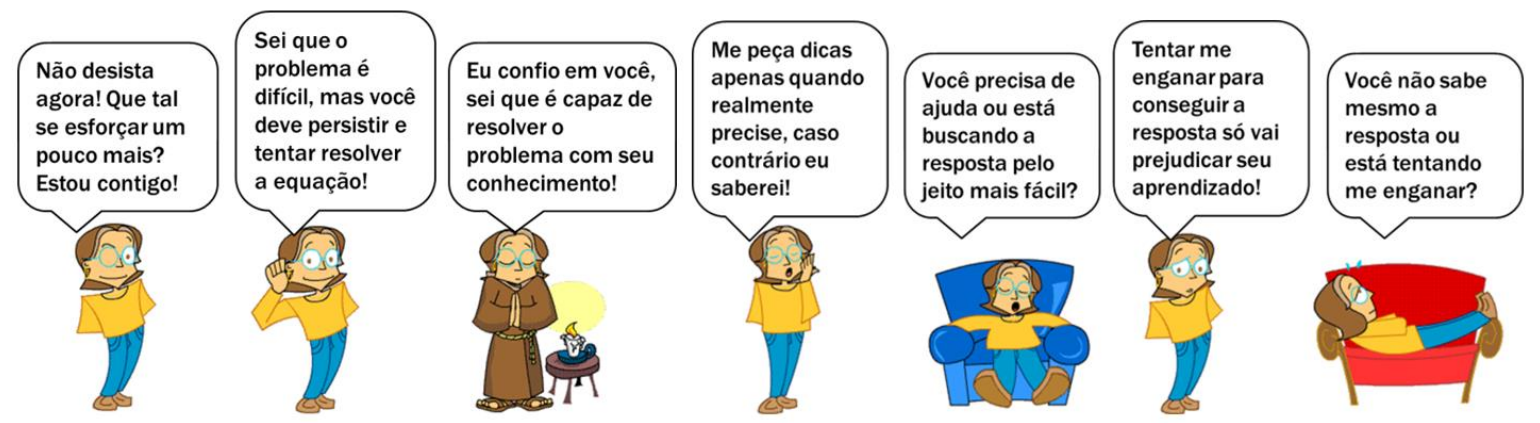

Figura 3: Comportamentos do agente em suas duas versões

\subsection{Definição de traços de personalidade pa- ra o agente}

Com base nos conceitos apresentados por Reeves e Nass [42], decidiu-se por estabelecer o comportamento do agente com dois traços principais de personalidade: a preocupação com o aprendizado do aluno e a desconfiança de que o aluno estava tentando obter a resposta através das dicas.

O primeiro traço de personalidade se caracteriza por um agente mais amigável, que demonstra preocupação com a qualidade do aprendizado do aluno e sua motivação para os estudos. Tal comportamento é apresentado, conforme descrito na subseção anterior, quando o agente entende que o aluno está fazendo Gaming The System. A Tabela 1 exibe as frases longas utilizadas nas intervenções do agente, todas elas elaboradas com o auxílio de uma professora de matemática.

Em relação às animações do agente ao exibir essas frases, são três animações diferentes, apresentadas na Figura 3. Em uma delas o tutor age demonstrando cumplicidade com o aluno, na outra ele demostra prestar atenção no aluno e, na última, ele assume uma postura de conselheiro. Os comportamentos foram escolhidos de modo a refletir o sentimento que ele tenta despertar no aluno com o comentário, de motivação e foco no aprendizado. Traçando um paralelo com o estudo de Reeves e Nass [42], essas abordagens visam demonstrar positivismo para o aluno, incentivando-o a utilizar as dicas de maneira correta e a tentar resolver os problemas através do próprio esforço. As mensagens longas foram intercaladas com mensagens curtas, conforme descrito anteriormente, no sentido de tornar menos estático e previsível o comportamento do tutor. Essas mensagens estão relacionadas na Tabela 2, para os dois comportamentos diferentes do agente.
Tabela 2: Frases curtas do agente nas duas formas de manifestação

\begin{tabular}{|l|l|}
\hline \multicolumn{1}{|c|}{ Amigável } & \multicolumn{1}{c|}{ Crítico } \\
\hline Sei que você consegue! & Precisa mesmo de ajuda? \\
\hline Conto com você! & Estou de olho em você! \\
\hline Continue se esforçando! & Está tentando me enganar? \\
\hline Não desista agora! & Quer que eu te dê a resposta? \\
\hline $\begin{array}{l}\text { Você capaz de superar } \\
\text { isso! }\end{array}$ & $\begin{array}{l}\text { Você está pedindo ajudas } \\
\text { demais! }\end{array}$ \\
\hline
\end{tabular}

No que tange ao segundo traço de personalidade, o agente que manifesta esse comportamento demonstra desconfiança do aluno quando ele pede ajudas consecutivas e, inclusive, sugere que isso foi feito na tentativa de obter a resposta da maneira mais simples. Ao entender que o aluno praticou o Gaming The System, o agente começa a interceder de maneira rígida e crítica em relação ao comportamento do aluno sobre o uso de dicas.

Sobre os comportamentos demonstrados pelo agente com a postura mais crítica em relação às ações do aluno, ele exibe quatro animações diferentes que são apresentadas na Figura 3. Em uma ele se mostra triste, como quem está decepcionado com as ações do aluno, em outras duas ele se mostra cansado e desmotivado e na última ele se mostra indiferente ao aluno, como se a ocorrência do Gaming The System motivasse essas reações.

Analisando do ponto de vista do tipo de personalidade demonstrada pelas ações, conforme a divisão proposta por Reeves e Nass [42], ambas são dominantes. Isso se faz necessário para, inclusive, auxiliar na credibilidade do agente e fazer com que o aluno o respeite tal qual faria com um professor. Piaget [40] sugere que a construção desse respeito é fundamental na relação professor-aluno e que inclusive é benéfica para essa relação e também para $\mathrm{o}$ aprendizado. 


\section{Avaliação}

Após a implementação dos agentes, um experimento foi conduzido com 41 alunos de 2 turmas de $8^{\text {a }}$. série de uma escola privada de Porto Alegre. Desses, os dados de 4 alunos foram desconsiderados por não terem resolvido nenhuma equação no sistema, resultando em 37 alunos analisados. Os arquivos de log foram analisados para verificar a ocorrência do comportamento durante as interações com o tutor.

Os alunos que participaram da avaliação foram divididos em três grupos: (i) o primeiro grupo, formado por 13 estudantes, utilizou o PAT2Math sem nenhum agente animado; (ii) outros 13 alunos utilizaram o agente que lidava com o Gaming The System através da estratégia mais amigável; (iii) e o terceiro grupo, que utilizou o agente de comportamento mais rígido e desconfiado, contava com 11 alunos. Ambas as turmas foram divididas aleatoriamente nestes três grupos, de acordo com a versão do sistema. A escolha da versão é realizada automaticamente pelo sistema durante o cadastro do aluno. A diferença entre as versões é mostrada na Figura 4.

Os alunos interagiram em média durante 50 minutos com o tutor PAT2Math. Mais especificamente, os alunos deveriam resolver uma lista de equações na ferramenta PATEquation do tutor. Todas as outras funcionalidades do tutor foram desativadas, uma vez que objetivo era verificar a ocorrência do Gaming The System, que pode acontecer apenas na resolução de exercícios. No caso do tutor PAT2Math, os exercícios consistem na resolução de equações no módulo PATEquation. As equações eram apresentadas em ordem aleatória, de forma que cada aluno resolvesse uma equação diferente ao mesmo tempo. $\mathrm{O}$ objetivo era que os alunos não se sentissem motivados a copiar a resposta do colega no computador mais próximo, no lugar de resolver a equação. Não foi estabelecido uma quantidade mínima de equações para o aluno resolver, sendo que a quantidade máxima de equações disponíveis era 50. Nenhum aluno resolveu as 50 equações. O sistema manteve um log de todas as ações e pedidos de ajuda realizados pelo aluno.

Inicialmente, foi realizada uma demonstração aos alunos de como utilizar o PATEquation para resolver equações. Após foi explicado aos alunos como se cadastrar e como se logar no sistema. Após cadastro e login, os alunos foram liberados para interagir livremente com o sistema. A pesquisadora apenas interagiu com os alunos quando eles chamavam para perguntar o funcionamento de um botão ou opção do sistema. Os alunos não foram auxiliados em relação à resolução da equação. Foram analisados os logs de uso do tutor para que fosse possível identificar quantas vezes os alunos pediram ajuda e quantas vezes o tutor entrou em ação, demonstrando o comportamento ao qual ele se propõe. A comparação das variações apresentadas nestes números permite que se avalie a influência do tutor sobre o comportamento $G a$ - ming The System e, inclusive, sobre as reações dos alunos após as ações do tutor. Por fim, essa avaliação permite identificar e entender qual implementação se mostrou mais efetiva na prevenção do comportamento.

Os três grupos de alunos foram avaliados sob três parâmetros diferentes: ocorrência do Gaming The System verificada nos logs; número de dicas solicitadas; e, por fim, número de equações resolvidas. Em função de a pesquisa estar avaliando três grupos ao mesmo tempo e ter o intuito de verificar se foram as diferenças entre eles a causa da variação nos resultados aferidos, optou-se por utilizar ANOVA para a análise estatística dos dados.

No que diz respeito ao primeiro critério avaliado, Gaming The System, obteve-se os valores apresentados na Tabela 4 para média (m) e desvio-padrão (dp) de cada grupo. Aplicando o ANOVA, obteve-se os seguintes valores: $\mathrm{p}=0.36 ; \mathrm{F}=1.034$. $\mathrm{O}$ valor não é estatisticamente relevante, o que não permite verificar que houve diferença significativa entre os grupos. Porém, há alguns pontos a se destacar individualmente entre os grupos. O grupo que utilizou o agente crítico foi onde se percebeu a menor ocorrência de Gaming The System. O grupo que utilizou o agente amigável foi o segundo nesse sentido, enquanto o grupo que utilizou o tutor sem agente teve a maior ocorrência do mau comportamento.

O segundo critério levado em conta na avaliação foi o número de dicas que os alunos pediram durante a interação com o tutor (ver Tabela 4). Dentro disso, a aplicação da ANOVA não trouxe resultados significativos ( $\mathrm{p}=0.24$; $\mathrm{F}=1.511$ ). Novamente, é permitida a análise individual destes dados, onde o grupo com o agente crítico foi o que menos pediu dicas, sendo seguido pelo grupo que utilizou o tutor sem agente e, como o grupo que mais pediu dicas, o que utilizou o PAT2Math com o agente amigável.

Por fim, foi avaliado o número de equações que os alunos conseguiram resolver completamente dentro do tempo de interação com o tutor, aproximadamente 50 minutos, foram desconsideradas resoluções parciais (ver Tabela 4). Esse, por sua vez, foi o critério em que o resultado é menos significativo ( $\mathrm{p}=0.78 ; \mathrm{F}=0.250)$. Um ponto a se considerar nesse quesito é que os alunos que lidaram com o tutor com o agente crítico resolveram significativamente menos equações se comparados aos outros grupos. Buscou-se igualmente entender se a presença do agente teria influência no comportamento dos alunos, comparando, através de um teste t não pareado, os dados dos alunos que interagiram com o tutor sem agente (Grupo 1) frente aos alunos que interagiram com algum dos agentes implementados (Grupo 2 e Grupo 3). Nessa análise, os testes não apresentaram valores significativos, o que permite entender que a presença do agente não influi diretamente sobre os pontos analisados. Com relação aos resultados, para a ocorrência do Gaming The System, dicas solicitadas e equações resolvidas, os valores atribuídos à p e $\mathrm{t}$, respectivamente, foram $0.37(\mathrm{t}=0.90), 0.40$ $(\mathrm{t}=0.84), 0.81(\mathrm{t}=0.24)$ para $\mathrm{df}=34$. 

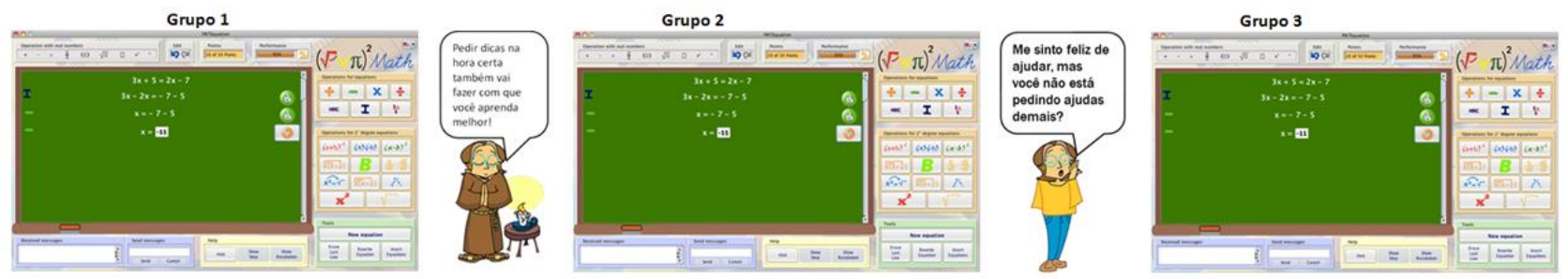

Figura 4: Diferentes versões do tutor utilizadas na avaliação

Tabela 3: Resultados das análise utilizando ANOVA

\begin{tabular}{|c|c|c|c|c|}
\hline Critério & Versão do tutor & Média & Desvio Padrão & Total de ocorrências \\
\hline \multirow{3}{*}{$\begin{array}{l}\text { Gaming The } \\
\text { System }\end{array}$} & Agente Crítico & 1.82 & 1.60 & 20 \\
\hline & Agente Amigável & 2.69 & 1.75 & 35 \\
\hline & Sem Agente & 3.00 & 2,61 & 39 \\
\hline \multirow{3}{*}{$\begin{array}{l}\text { Dicas solici- } \\
\text { tadas }\end{array}$} & Agente Crítico & 2.73 & 1.95 & 30 \\
\hline & Agente Amigável & 6.00 & 5.82 & 78 \\
\hline & Sem Agente & 4.08 & 4.92 & 53 \\
\hline \multirow{3}{*}{$\begin{array}{l}\text { Equações Com- } \\
\text { pletas }\end{array}$} & Agente Crítico & 7.55 & 4.97 & 83 \\
\hline & Agente Amigável & 8.77 & 4.38 & 114 \\
\hline & Sem Agente & 8.54 & 4.01 & 111 \\
\hline
\end{tabular}

Um ponto importante a salientar no que tange aos dados avaliados é a ocorrência de alguns incidentes durante as avaliações. Tais incidentes podem ter influenciado em relação aos resultados medidos, seja por afetarem questões motivacionais do aluno ou a própria interação com o tutor. São eles: indisponibilidade momentânea do servidor, o que fez com que uma primeira avaliação com outras duas turmas tivesse de ser totalmente descartada em função da não completude dos arquivos de logs; e dificuldades com a resolução dos monitores utilizados nos testes, o que fez com que alguns alunos não vissem o agente o tempo todo durante a interação com o tutor.

\subsection{Discussão}

O primeiro ponto a ser levado em consideração é a efetividade das implementações apresentadas ao lidar com o comportamento Gaming The System. Nesse sentido, o agente crítico se mostrou mais efetivo, o que vai ao encontro dos pontos apresentados por Reeves e Nass [42], onde mídias negativas marcam mais as pessoas que as positivas. Além disso, mídias negativas tendem a atrair mais a atenção.

Um ponto a se destacar neste caso é que a criticidade do agente pode ter inibido os pedidos de dicas, mesmo os necessários, uma vez que os alunos que interagiram com tal tutor pediram menos dicas. Além disso, os alunos que interagiram com o agente crítico resolveram, em média, menos equações no período de interação, mais um indicador de que o comportamento do agente influenciou na maneira como os alunos interagem com o tutor.

Os resultados dos testes com o agente afetivo, por sua vez, mostram uma relação interessante: com este agente, os alunos pediram mais dicas se comparados aos outros grupos, mas isso não configurou um aumento muito elevado na ocorrência do Gaming The System. Nesse caso, é válida a percepção a cerca de que a personalidade do agente influenciou na maneira como o aluno utilizou as dicas.

Em relação ao grupo que utilizou o tutor sem agente, ele serviu de parâmetro de comparação para que se pudesse chegar às discussões e resultados apresentados acima, mas não se mostrou o mais efetivo em nenhum dos quesitos avaliados. Isso corrobora com o que já foi apresentado de estudos prévios (ver seção 6) que ressaltam a relevância do uso de agentes animados para melhorar a motivação do aluno que interage com Sistemas Tutores Inteligentes. 


\section{Conclusões}

O presente estudo abordou o estado da arte no estudo do Gaming The System, consolidando toda a evolução de pesquisas sobre o assunto, bem como propondo uma abordagem original, e não restritiva em relação ao tema.

Baseado na hipótese de que o aluno faz o Gaming The System porque não considera o agente credível ou não o considera capaz de tomar medidas diante do mau comportamento, o estudo apresentou uma abordagem diferenciada, não testada até então, baseada em convenções sociais simples para suportar a relação tutor-aluno. Acredita-se que se o agente mostrar ao aluno que é ciente que o mesmo está fazendo Gaming The System pode inibir o comportamento por parte do aluno.

Com base no estudo apresentado, é possível, mesmo sem resultados significativos na análise estatística, verificar que a personalidade e abordagem do agente animado em relação ao aluno parecem influenciar no comportamento dele. $\mathrm{O}$ exemplo é evidenciado inclusive pelos resultados no que diz respeito a pedidos de dicas, onde o agente crítico reprimiu de certa forma os pedidos de ajuda enquanto o agente amigável foi mais solicitado pelo aluno e isso não influenciou na ocorrência do Gaming The System. Além disso, a presente pesquisa vem corroborar no que diz respeito às abordagens não restritivas ao comportamento dos alunos, tornando a experiência destes com o tutor, inclusive, mais antropomórfica e amigável. No entanto, devido aos problemas enfrentados nos experimentos de avaliação, faz-se necessária uma investigação mais aprofundada do objeto de estudo, com novos experimentos com um grupo maior de usuários.

Como estudos futuros, há uma série de oportunidades que podem ser elencadas, como a implementação de um agente com um modelo de personalidade mais consistente, de modo que seu padrão de comportamento fique ainda mais evidenciado e com características que demonstrem variação de emoções em relação às ações do aluno. Outro ponto a ser explorado é o tratamento do comportamento quando relacionado às tentativas de solução independente do problema, fazendo uso, inclusive, de estratégias motivacionais pedagógicas empregadas em sala de aula de modo a tornar o agente mais credível, tendo em vista aproximar a relação tutor-aluno da relação professor-aluno.

\section{Referências}

[1] ALEVEN, V. Helping Students to Become Better Help Seekers: Towards Supporting Metacognition in a Cognitive Tutor. Proceedings of German-USA Early Career Research Exchange Program: Research on Learning Technologies and Technology Supported Education, Tubingen, Germany. 2001.

[2] ALEVEN, V.; KOEDINGER, K. R. Limitations of Student Control: Do Students Know when they need help? 5th International Conference on Intelligent Tutoring Systems. 2000.

[3] ALMEIDA, A. R. S. A emoção na sala de aula. Campinas: Papirus, 1999.

[4] ANDERSON, J. R.; BOYLE, C. F.; CORBETT, A. T.; LEWIS, M. W. Cognitive Modelling and Intelligent Tutoring. Artificial Intelligence, v. 42, p. 7-49, 1990.

[5] ARROYO, I.; FERGUSON, K.; JOHNS, J.; DRAGON, T.; MEHERANIAN, H.; FISHER, D.; BARTO, A.; MAHADEVAN, S.; WOOLF, B. P. Repairing Disengagement with Non-Invasive Interventions. Proceedings of the 13th International Conference on Artificial Intelligence in Education, 195202, 2007.

[6] BAKER, R. S. (2007) Is Gaming the System Stateor-Trait? Educational Data Mining Through the Multi-Contextual Application of a Validated Behavioral Model. Complete OnLine. Proceedings of the Workshop on Data Mining for User Modeling at the 11th International Conference on User Modeling 2007, 76-80.

[7] BAKER, R. S. Gaming the System: A Retrospective Look. Philippine Computing Journal, v. 6, n. 2, p. 913, 2011.

[8] BAKER, R. S.; CORBETT, A. T.; KOEDINGER, K. R.; WAGNER, A. Z. Off-Task Behavior in the Cognitive Tutor Classroom: When Students "Game The System”. ACM CHI 2004: Computer-Human Interaction. 2004.

[9] BAKER, R. S.; CORBETT, A. T.; KOEDINGER, K. R.; EVENSON, S. E.; ROLL, I.; WAGNER, A. Z.; NAIM, M.; RASPAT, J.; BAKER, D. J.; BECK, J. Adapting to When Students Game an Intelligent Tutoring System8th International Conference on Intelligent Tutoring Systems. 2006.

[10] BAKER, R. S.; CORBETT, A. T.; KOEDINGER, K. R. Detecting Student Misuse of Intelligent Tutoring Systems7th International Conference on Intelligent Tutoring Systems.2004. 
[11] BAKER, R. S.; DE CARVALHO, A. M. J. A.; RASPAT, J.; ALEVEN, V.; CORBETT, A. T.; KOEDINGER, K. R. Educational Software Features that Encourage and Discourage "Gaming the System". Proceedings of the 14th International Conference on Artificial Intelligence in Education, p. 475482, 2009.

[12] BAKER, R.S.; GOWDA, S.M.; WIXON, M.; KALKA, J.; WAGNER, A.Z.; SALVI, A.; ALEVEN, V.; KUSBIT, G.; OCUMPAUGH, J.; ROSSI, L. Proceedings of Towards Sensor-free automated detection of affect in a Cognitive Tutor for Algebra5th International Conference on Educational Data Mining. 2012.

[13] BAKER, R. S.; WALONOSKI, J.; HEFFERNAN, N.; ROLL, I.; CORBETT, A.; KOEDINGER, K. Why Students Engage in "Gaming the System" Behavior in Interactive Learning Environments. Journal of Interactive Learning Research, v. 19 n. 2, 185224, 2008

[14] BECK, J. Engagement tracing: using response times to model student disengagement. Proceedings of the 12th International Conference on Artificial Intelligence in Education (AIED 2005), 88-95. 2005.

[15] BEAL, C. R.; QU, L.; LEE, H. Classifying learner engagement through integration of multiple data sources. Proceedings of the 21 st National Conference on Artificial Intelligence, July 16-20. Boston MA. 2006.

[16] BOSSA, N. A. Dificuldades de aprendizagem. Porto Alegre: Artes Médicas, 2000

[17] BUISINE, S.; MARTIN, J. C. The effects of speechgesture cooperation in animated agents' behavior in multimedia presentations. International Journal "Interacting with Computers: The interdisciplinary journal of Human-Computer Interaction, v. 19, p. 484493, 2007.

[18] CARBONELL. Al in CA!: An artificial intelligence approach to computer-assisted instruction. IEEE Transactions on Man-Machine Systems, v. 11, p. 190-202, 1970.

[19] COLlins, A. M.; STEVENS, A. L. A cognitive theory of inquiry teaching. In: Teaching knowledge and intelligent tutoring. Nor-Wood: Ablex Publishing, 1991.

[20] CORBETT, A.; KOEDINGER, K. R.; ANDERSON, J. R. Intelligent Tutoring Systems. In: Handbook of Human-Computer Interaction. Second ed. Amsterdam: Elsevier Science, p. 849-874. 1997.
[21] CORRÊA, D. W. DIVALITE: Um Framework para Criação de Agentes Animados para WEB. Trabalho de conclusão de curso (Bacharel em Ciências da Computação). Curso de Ciências da Computação. Universidade do Vale do Rio dos Sinos, São Leopoldo, RS, 2011.

[22] DAMÁSIO, A. R. O Erro de Descartes: emoção, razão e o cérebro humano. São Paulo: Companhia das Letras, 2001.

[23] FIGLIO, D. N.; GETZLER, L. S. Accountability, Ability and Disability: Gaming the System, 2002.

[24] GRAVINA, M. A.; SANTAROSA, L. M. A Aprendizagem da Matemática em Ambientes Informatizados. IV Congresso RBIE, Brasília, 1998.

[25] GONG, Y.; BECK, J.E.; HEFFERNAN, N.T.; FORBES-SUMMERS, E. The impact of gaming (?) on learning at the finegrained level. Proceedings of the 10th International Conference on Intelligent Tutoring Systems, p. 194-203, 2010.

[26] HARTMANN, B.; MANCINI, M.; PELACHAUD, C. Implementing Expressive Gesture Synthesis for Embodied Conversational AgentsGesture Workshop. Springer, 2005.

[27] HAYES-ROTH, B. Principles of Character Design. In: Life-Like Characters. Dordrecht: Kluwer Academic Publishers, 2003.

[28] HAYES-ROTH, B.; DOYLE, P. Animate Characters. In: Autonomous Agents and Multi-Agent Systems. Dordrecht: Kluwer Academic Publishers, 1998.

[29] JAQUES, P. A. Using an Animated Pedagogical Agent to Interact Affectivelly with the Student. Programa de Pós-Graduação em Ciência da Computação, Universidade Federal do Rio Grande do Sul, Porto Alegre, 2004.

[30] JAQUES, P.; VICARI, R. Estado da Arte em Ambientes Inteligentes de Aprendizagem que Consideram a Afetividade do Aluno. Revista Informática na Educação: Teoria \& Prática, v.8, n.1., 2005.

[31] JOHNSON, W. L.; RICKEL, J.; LESTER, J. Animated Pedagogical Agents: Face-to-Face Interaction in Interactive Learning Environments. International Journal of Artificial Intelligence in Education, v. 11, p. 47-78, 2000.

[32] KOEDINGER, K. R.; CORBETT, A. T. Cognitive tutors: technology bringing learning science to the classroom. In: The Cambridge Handbook of the Learning Sciences. Cambridge: [s.n.]. p. 61-77, 2006. 
[33] KOEDINGER, K. R.; ANDRESON, J. R.; HADLEY, W. H.; MARK, M. A. Intelligent Tutoring Goes To School in the Big City. International Journal of Artificial Intelligence in Education (IJAIED), v. 8, p. 30-43, 1997.

[34] LESTER, J. C.; CONVERSE, S. A.; KAHLER, S. E.; BARLOW, S. T.; STONE, B. A.; BHOGAL, R. S. The persona effect: Affective impact of animated pedagogical agents. SIGCHI conference on Human factors in computing systems. Atlanta: 1997.

[35] LOYALL, A. B.; BATES, J. Personality-rich believable agents that use language.First International Conference on Autonomous Agents (Agents'97). Marina del Rey: ACM Press, 1997.

[36] MARCHAND, M. A Afetividade do Educador. 4. ed. São Paulo: Summus, 1985.

[37] MOTOLA, R.; JAQUES, P. A.; AXT, M.; VICARI, R. Architecture for animation of affective behaviors in pedagogical agents. São Leopoldo, 2009.

[38] MULDNER, K.; BURLESON, W.; VAN DE SANDE, B.; VANLEHN, K. An analysis of students' gaming behaviors in an intelligent tutoring system: Predictors and impacts. User Modeling and User-Adapted Interaction, v. 21 n.1-2, p. 99-135, 2011.

[39] PEREIRA, A. S. Um Estudo de Aplicações de Ensino na Internet Orientada a Agentes. Porto Alegre, 1997.

[40] PIAGET, J. Seis estudos de psicologia. 21. ed. Rio de Janeiro: Forense Universitária, 1995.

[41] PSOTKA, J.; MASSEY, L. D.; MUTTER, S. Intelligent Tutoring Systems: Lessons Learned. New Jersey: Lawrence Erlbaum Associates Ltd, 1988.

[42] REEVES, B.; NASS, C. The Media Equation: How People Treat Computers, Television, and New Media Like Real People and Places. Stanford: Center for the Study of Language and Inf, p. 305, 2003.

[43] ROLL, I.; ALEVEN, V.; MCLAREN, B.M.; KOEDINGER, K.R. Improving students' helpseeking skills using metacognitive feedback in an intelligent tutoring system. Learning and Instruction, v. 21, p. 267-280, 2011.

[44] SEFFRIN, H.; RUBI, G.; CRUZ, B.; JAQUES, P. Resolvendo equações algébricas no STI PAT2MathSimpósio Brasileiro de Informática na Educação. João Pessoa: 2010.

[45] SEFFRIN, H.; RUBI, G.; JAQUES, P. O modelo cognitivo do Sistema Tutor Inteligente PAT2MathSimpósio Brasileiro de Informática na Educação. Aracaju: 2011.
[46] STEVENS, A. L.; COLLINS, A. M. The goal structure of a Socratic tutorACM Conference. New York: Association for Computing Machinery, 1977.

[47] TAIT, K.; HARTLEY, J. R.; ANDERSON, R. C. Feedback procedures in computer-assisted arithmetic instruction. British Journal of Educational Psychology, v. 46, n. 2, p. 161-171, 1973.

[48] VANLEHN, K. The behavior of tutoring systems. International Journal of Artificial Intelligence in Education, v. 16, n. 3, p. 227-265, 2006.

[49] VYGOTSKY, L. S. Pensamento e Linguagem. Rio de Janeiro: Martins Fontes, 1998.

[50] WALLON, H. As origens do pensamento na criança. São Paulo: Manole, 1989.

[51] WAlONOSKI, J. A.; HEFFERNAN, N. T. Prevention of OffTask Gaming Behavior in Intelligent Tutoring Systems. Proceedings of the 8th International Conference on Intelligent Tutoring Systems, p. 722724, 2006.

[52] WOOLF, B. P. Building Intelligent Interactive Tutors: Student-centered strategies for revolutionizing e-learning. Burlington: Morgan Kaufmann. 2009.

[53] WOOLF, B. P.; MCDONALD, D. D. Building a computer tutor: Design issues. IEEE Computer, v. 17 , p. $61-73,1984$ 